\title{
Structural unsafety revealed by failure databases
}

1 Karel Terwel MSc

Lecturer and Researcher in Structural Design and Safety, Faculty of Civil Engineering and Geosciences, Delft University of Technology, Delft, the Netherlands
2 Wouter Boot MSC, LLM

Structural Engineer, Brunel Nederland, the Netherlands

3 Mirjam Nelisse MSC

Technical Consultant Safety and Risk and Project Leader of $A B C$ Registration, TNO, Delft, the Netherlands
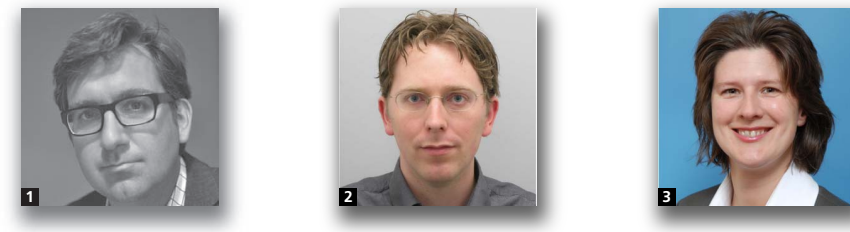

After several major structural incidents in the Netherlands, such as the collapse of five balconies in Maastricht in 2001 resulting in two fatalities, various initiatives have been started to improve structural safety. Research studies were initiated on the characteristics, causes and consequences of structural incidents. In this paper the results of three of these research studies are compared. Each study uses different data sources: a confidential reporting system called $A B C$ registration, Dutch arbitration awards on functional and structural failures and a study of structural incidents mentioned in a newspaper for the building industry, called Cobouw. A comparison of the results shows variations due to the type of sources used. However, general patterns have been derived from the three studies. The cause of structural failure on average was approximately $35 \%$ in the design phase, approximately $30 \%$ in the construction phase and approximately $10 \%$ in the use and maintenance phase. This paper shows that contrasting and combining results of different sources has improved the overview of structural incidents and has provided an insight into trends.

\section{Introduction}

\subsection{Major failures worldwide}

Structural failures happen at all times and places. Examples range from the collapse of medieval churches to the collapse of a garment factory in Savar, Bangladesh, in 2013. They are not limited to specific parts of the world; every western country also has its own major disaster/s. After such an event, usually initiatives are put in place to avoid repetition of similar failures in the future. The investigation of structural incidents provides a basis for these initiatives.

\subsection{Failure databases worldwide}

In the past, various international database studies have been executed that include a comparison of structural failures. A starting point for many of these studies is the renowned research of Schneider and Matousek (1976), who investigated 800 failures provided by insurance companies. They concluded that many of the failures could have been avoided by effective control.

Furthermore, the Architecture and Engineering Performance Information Center (AEPIC) was established in Maryland,
USA, to collect, analyse and disseminate information from incidents with the aim of learning from failures (Loss, 1987). This was a unique initiative, because until that time no comprehensive reference of accessible data on performance of structures was available throughout the world. However, like many of these initiatives, it stopped after some years owing to lack of funding.

More recently Fruehwald et al. (2007) compared the results from Schneider and Matousek with eight other studies and added another 126 timber failure cases to this pool of international data. Some other database initiatives are briefly discussed in Breysse (2012). In addition to these, in the Netherlands some databases on structural failures have been recently developed. This paper focuses on a comparison of the Dutch database initiatives.

\subsection{Major failures in the Netherlands}

In the last decade some major structural incidents have occurred in the Netherlands. Two of these major collapses will be briefly discussed: the collapse of balconies in Maastricht 
in 2003 and the collapse of a roof structure for a new extension of the FC Twente stadium in 2011.

\subsubsection{Balconies in Maastricht: Patio Sevilla (Van Herwijnen, 2009; CUR, 2010)}

In 2003 a residential building called Patio Sevilla was completed. Just a few months later, five balconies of this apartment building collapsed, resulting in two fatalities. Several major investigations were started.

The structure of the balconies consisted of prefabricated concrete slabs. Every balcony slab was connected at two positions with the floor slab by thermally isolating connectors and at one position with a steel column $100 \mathrm{~mm} \times 100 \mathrm{~mm}$ (see Figure 1 for a top view of the standard balconies).

Some design changes were made that were relevant to the failure. First, for aesthetic reasons the column was repositioned towards the borders of the slab (in Figure 1 to the left side), thus resulting in the introduction of a ridge on the side of the balcony slab (see concrete ridge underneath column in Figure 1). Second, the lowest balcony slab was reduced in thickness during construction for financial reasons.

For the design and construction of the balconies many parties were involved. An engineer of record was responsible for the design. A main contractor hired subcontractors for the balconies and the columns, which is common practice in the Dutch building industry.

During construction some cracks were detected on the lowest balcony slab. It appeared that the ridge on the ground floor underneath the column was not adequately supported by the foundation wall, because of the reduced thickness of the slab. This problem seemed to be fixed by applying a steel support

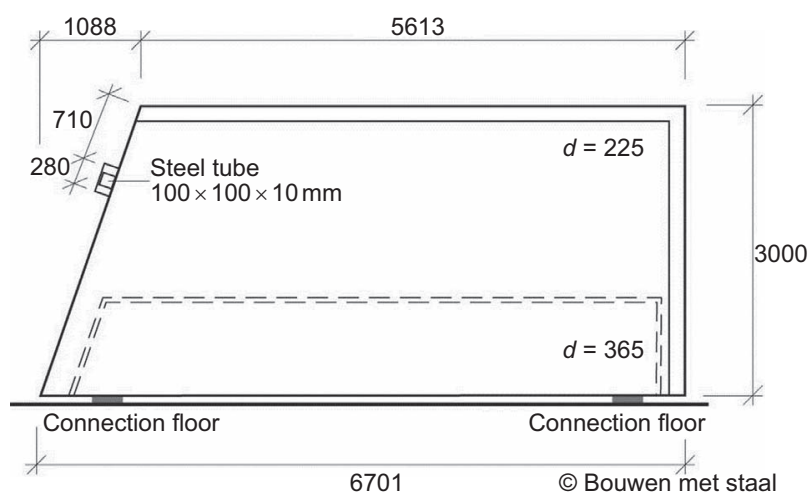

Figure 1. Top view of standard balconies with supporting structure (all dimensions in $\mathrm{mm}$ ) (reproduced by permission of Bouwen met Staal) underneath the concrete ridge (see Figure 2). The heavily loaded, $100 \mathrm{~mm} \times 100 \mathrm{~mm}$ column was by this means supposed to be adequately supported.

The investigations focused on various parts of the structure. The connections between the prefabricated balconies and the floors proved to be adequate. When the lowest support of the columns on the concrete ridge was investigated (Figure 2), it appeared that the bolted connection of the steel support on the foundation wall was not adequate and the connection between the steel support and the concrete ridge was suboptimal. Finally, experts revealed that, in addition to some other contributing factors, the combination of a bending moment and a concentrated force on the small ridge resulted in failure of the ridge. A progressive collapse followed when the columns were not supported any longer by the lowest ridge.

The engineer of record was convicted, with a fine of $€ 22500$, by a criminal court because no adequate control had been performed on detailing of the ridge and after the discovery of cracks in the ridges no further investigations were performed. The criminal cases against the main contractor and the engineering of the balconies resulted in an acquittal.

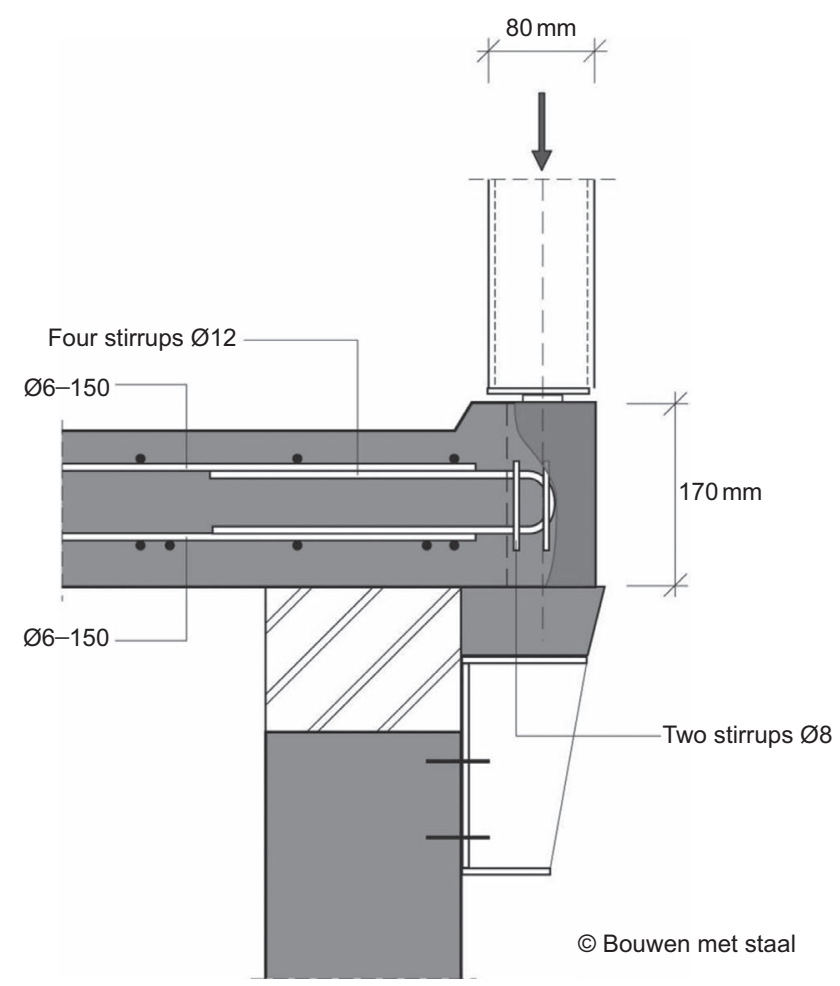

Figure 2. Detail of failed ridge (reproduced by permission of Bouwen met Staal) 
This case was a wake-up call for the Dutch building industry, resulting in many initiatives to improve structural safety, such as a confidential reporting system for building mistakes.

\subsubsection{Roof stadium FC Twente (Dutch Safety Board, 2012)}

In 2011 the roof of an extension for the FC Twente stadium collapsed during construction, resulting in two fatalities and nine injuries (Figure 3). The roof structure consisted of a cantilevering steel structure with steel sheeting, which was stabilised by bracings. In addition to the usual loads, the roof structure had to deal with some heavy video screens. This extension was constructed by the same combination of (sub)contractors that constructed an earlier extension successfully in 2008, thus resulting in a large amount of trust between parties involved.

Investigation by the independent Dutch Safety Board showed that the construction of the main load-bearing structure was not completed and stabilised when the finishing structure was applied. Essential connecting bars for the final structure were not in place, and temporary bracings were removed to apply safety nets. At the moment of collapse the roof was already loaded with hanging bridges, labourers, stacked roof sheets and the video screen. Furthermore the structure deviated from the intended dimensions.

According to the investigation report, these aspects contributed to the collapse of the roof. Influencing factors for the incident were: the tight planning resulting in a suboptimal construction sequence and unclear boundaries between the various phases during construction; too little attention to the method of execution during design; unjustified trust resulting

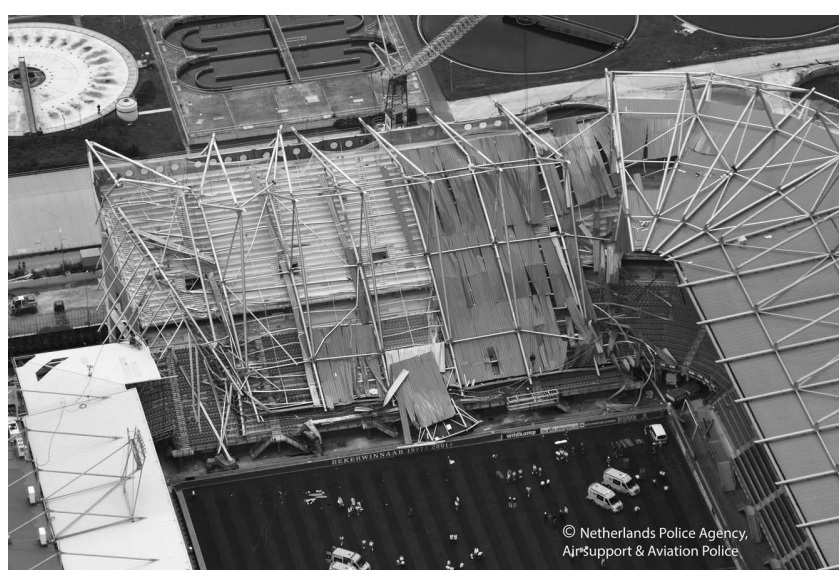

Figure 3. Roof of FC Twente stadium after collapse (reproduced by permission of Netherlands Police Agency: Air Support and Aviation Police) in insufficient coordination and control; and insufficient allocation of responsibilities resulting in a failure to execute tasks.

After this case the Dutch Safety Board doubted whether the Dutch building industry was really learning from its failures, because the causes were not unique and represented a repetition of earlier failure cases.

\subsection{Failure databases in the Netherlands}

Although in-depth research of cases like these ones will provide insight into individual causes and consequences, to value the state of structural safety in the Netherlands it is necessary to acquire more data over a broader range, from various sources. In the Netherlands several databases related to structural failures have been established. Three of these recent initiatives are the subject of this paper.

A 'Cobouw database' was set up in 2004 by TNO (Netherlands Organisation for Applied Scientific Research) based on 230 structural failures that were reported in the Cobouw (Dieteren and Waarts, 2009), a leading newspaper for the Dutch building industry. Delft University of Technology developed a similar database, elaborating on the format used by TNO. It currently includes 401 incidents based on Cobouw articles between 1993 and 2009. The results of this database were made available in 2012 (Terwel, 2012).

'ABC registration' was initiated in 2007 by the Platform on Structural Safety. It is a confidential reporting system of mistakes in structural design, execution, use/maintenance and demolition, which was set up by TNO (Terwel et al., 2012). The essence of this system is similar to 'Cross' in the UK. Anyone in the building industry can report mistakes through a website. These mistakes are anonymised and analysed by structural experts, who publish their results in periodic reports and newsletters. Although the last report dates from July 2011, consideration is being given to further reports.

The 'arbitration database' was developed in 2010 in a master's thesis containing 151 structural and functional failures extracted from arbitration awards of the Dutch arbitration institute for construction disputes from 1992 to 2009 (Boot, 2011). Arbitration is a common means of construction dispute resolution in the Netherlands.

The choice of boundary conditions, for instance the definition of failure and the way of categorising failures, varied for the three studies, making a direct comparison of their outcomes somewhat challenging. However, after thorough analysis and minor adjustments of some categories, useful results were obtained. Unfortunately, not all categories could be compared as each source provided different types of data about failures. 


\subsection{Main research question}

The research question that is answered in this paper is: 'What patterns can be detected from the comparison of various sources of data on structural failures and near misses in the Netherlands?'. These patterns consist of the characteristics of failures, such as type of buildings and materials, type of damage, causes and consequences. The focus is on the cases from Cobouw, ABC registration and Dutch arbitration awards. Part of this paper was presented as a conference paper at the Institution of Civil Engineers' Fifth International Conference on Forensic Engineering in London (Terwel et al., 2013).

\section{Results from incident investigations}

Tables 1 and 2 present an overview of the process of data gathering and analysis and of the outcomes of the three database studies on incidents.

\section{Explanation of results}

\subsection{Reliability of incident investigations}

The reliability of the incident investigations is determined by the reliability of the data and the reliability of the analysis process. A perfect analysis can never compensate for poor data. It appears that the reliability of the investigations of the $\mathrm{ABC}$ registration and Dutch arbitration awards is better than the reliability of the investigations in the Cobouw cases. The main reason is that generally the reliability of the data of the newspaper articles is expected to be limited. A more extensive discussion of the reliability of the investigations is presented in Terwel et al. (2013).

\subsection{Characteristics of cases and their damage}

\subsubsection{Number of incidents}

In Figure 4 incidents from all three studies are depicted with their date of occurrence. Fifty-four of the arbitration awards are not depicted because the date of occurrence of damage is not known.
In total, 741 cases are included in the databases for a period of over 20 years. This is a considerable number for analysis, but it should be noted that it is just a small proportion of all building mistakes. It was estimated for the Dutch building industry that yearly 20000 building mistakes are made, although not all necessarily lead to failure (Nelisse and Terwel, 2011).

From the figures of the Cobouw database, there seems to be an increase in number of failures during the period 1991-2007. This rise in failures over the years might be explained by an increase in media attention after major failures and a growing litigiousness. However, the increase is in line with an estimated increase of failure costs (USP Marketing Consultancy, 2008).

\subsubsection{Type and function of structures}

Figure 5 shows that approximately $85 \%$ of all incidents in the databases relate to buildings. In comparison, buildings count for approximately $74 \%$ of the yearly turnover in the construction sector (EIB, 2012). If it is assumed that the percentage of annual turnover is equivalent to the relative share of buildings in the total number of structures; this indicates that buildings seem to be slightly more vulnerable to failures than civil structures.

Figure 6 shows that approximately $40 \%$ of the cases have a residential function. About $55-60 \%$ of the annual turnover of all new buildings in the Netherlands is accounted for by residential buildings. It is possible that, because there are many small houses, structural failures of individual houses are not worth mentioning in newspapers, or the damage costs are too small to start an arbitration procedure. Nevertheless, it seems reasonable to draw the conclusion that residential buildings suffer relatively less often from structural failures. This might be explained by the fact that in the Netherlands houses are often produced in series, where repetition reduces the probability of failure. In addition, owing to demands in relation to sound and heat insulation, floors and walls in residential buildings usually have larger dimensions than are strictly

\begin{tabular}{llll}
\hline & Cobouw & ABC registration & Dutch arbitration awards \\
\hline Source of data & $\begin{array}{l}\text { (Near) failures collected by using } \\
\text { search terms in a digital archive of } \\
\text { newspaper Cobouw }\end{array}$ & $\begin{array}{l}\text { Voluntary reports of building } \\
\text { participants. Over } 80 \% \text { from local } \\
\text { building control officers and } \\
\text { structural engineers }\end{array}$ & $\begin{array}{l}\text { Arbitration awards found by } \\
\text { using search terms in an online } \\
\text { database of arbitration awards }\end{array}$ \\
$\begin{array}{llll}\text { Definition failure } \\
\text { case }\end{array}$ & $\begin{array}{l}\text { Every case where the (probability } \\
\text { of) failure of a (temporary) structure } \\
\text { (potentially) endangers persons }\end{array}$ & $\begin{array}{l}\text { Near misses without damage and } \\
\text { failures with damage. A building } \\
\text { mistake is defined as an error in } \\
\text { design, execution, use or mainte- } \\
\text { nance, threatening structural safety }\end{array}$ & $\begin{array}{l}\text { Cases with insufficient } \\
\text { functional or structural } \\
\text { herformance. Usually damage }\end{array}$ \\
& & haccurred
\end{tabular}

Table 1. Information on process of data gathering 


\section{Outcomes}

Number of incidents 401

Years of detection failure

Type of structures

Function of buildings

Material

Construction elements

Type of damage

Time of discovery

Phase of main cause

Type of error

\section{Pre-1990-2009}

$72 \%$ buildings, eight cases unknown

$38 \%$ residential, two cases unknown $28 \%$ concrete, $31 \%$ steel $/$ metal 62 cases unknown

$24 \%$ facades, $15 \%$ floors, one case unknown (only buildings regarded)

51\% (partial) collapse, 29\% structural damage, two cases other

\section{3 (yearly: $/ 17=2 \cdot 5$ )}

$21 \%$ construction, $67 \%$ use, two cases unknown $15 \%$ design phase, 30\% construction phase, $23 \%$ use phase, $17 \%$ combination, 120 cases unknown

$16 \%$ design error, $43 \%$ construction error, $16 \%$ combination, $8 \%$ use error,

$17 \%$ force majeure and other, 128 cases unknown
189

2000-2011

97\% buildings

$40 \%$ residential

$24 \%$ concrete, $38 \%$

reinforcement

$23 \%$ foundations, $21 \%$

floors

$84 \%$ no damage

0

$27 \%$ design, $50 \%$

construction

$61 \%$ design phase, $31 \%$

construction phase

$65 \%$ design error, 35\%

construction error
151

Pre-1990-2009

$91 \%$ buildings, two cases unknown $43 \%$ residential, 26 cases unknown $26 \%$ concrete, over $26 \%$ steel/ metal, 32 cases unknown $19 \%$ foundations, $19 \%$ roofs, two cases unknown

27\% (partial) collapse, 33\% structural damage, 33\% insufficient functionality, one case other

1

$25 \%$ construction, $67 \%$ use, nine cases unknown $26 \%$ design phase, $30 \%$ construction phase, $19 \%$ combination, 16 cases unknown

$34 \%$ design error, 33\% construction error, $23 \%$ combination, $3 \%$ use error, $6 \%$ material deficit, $1 \%$ other, 15 cases unknown

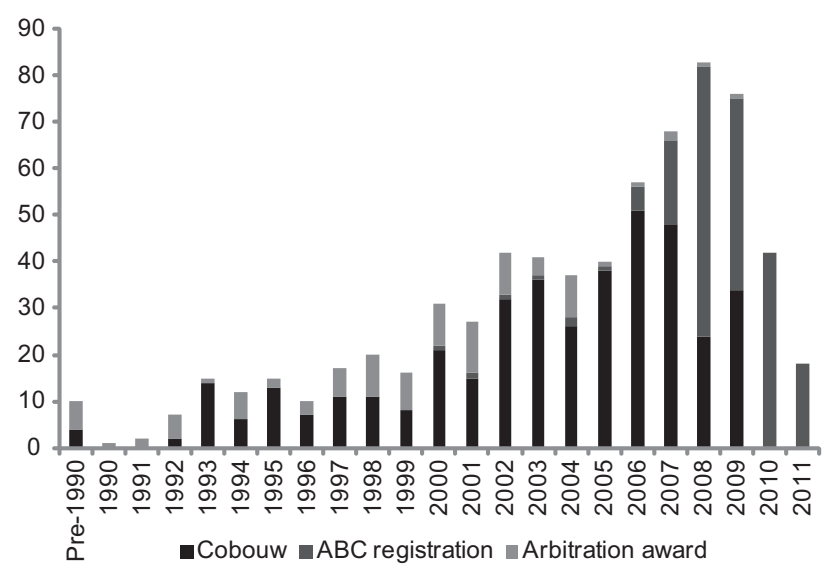

Figure 4. Number of incidents of all sources depicted for the year of occurrence of damage or, if no damage resulted, for the year of the mistake necessary for structural reasons. This might result in a larger redundancy for housing.

\subsubsection{Materials}

Figure 7 shows that the frequency of failure cases with concrete and steel/metal is similar. It seems that steel structures are more prone to errors, because concrete structures are more common than steel structures in the Netherlands. However, reliable data on the exact ratio of steel and concrete structures are not available.

Unlike the other research studies, the $\mathrm{ABC}$ registration recorded relatively more problems with reinforcement. It seems likely that the local building control, which reported nearly $70 \%$ of the cases, more often focuses on reinforcement deviations.

\subsubsection{Construction elements}

Figure 8 presents the construction elements that were damaged. The total average share of roofs, balconies, beams and floors is $38 \%$, whereas the total average share of facades, walls 


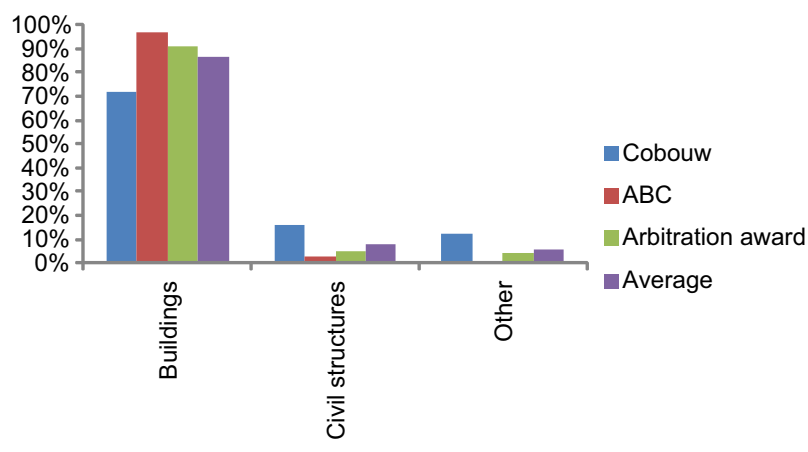

Figure 5. Type of structures

and columns is $24 \%$. When it is assumed that a building has roughly an equal number of horizontal and vertical elements it can be concluded that horizontal elements are more vulnerable to failures than vertical elements. This can be explained by the mechanical behaviour; the governing forces in columns are normal forces, whereas the governing forces in horizontal elements are usually bending moments. The latter situation usually results in a more sophisticated structural behaviour, thus increasing the probability of failure. Failures of foundations are also common, which is to be expected because of soft soils and erratic soil profiles in the Netherlands.

The type of damage to the construction elements ranges from (partial) collapse, to material deterioration, to insufficient functionality with no consequences. In particular for the ABC registration, over $80 \%$ of the cases reported no damage, because the failures were detected in time. Over $90 \%$ of the structures in the cases of Cobouw and arbitration awards showed damage.

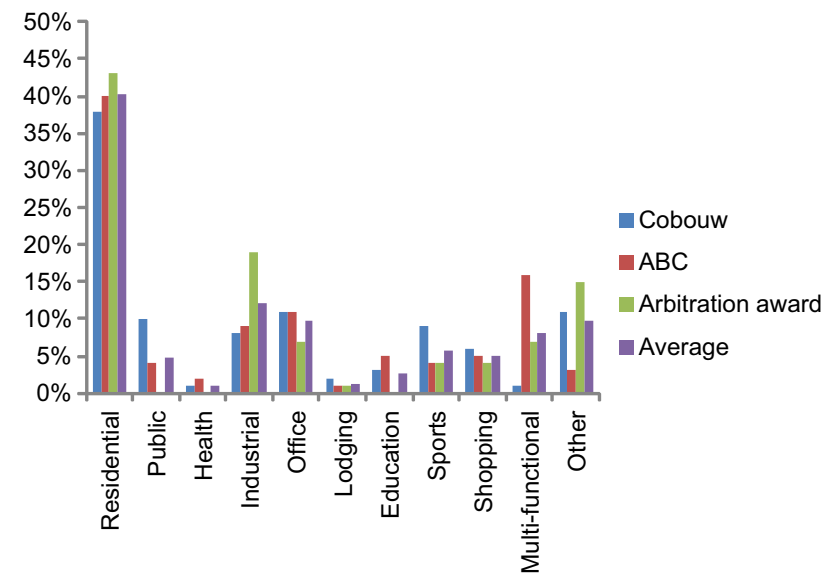

Figure 6. Function of buildings

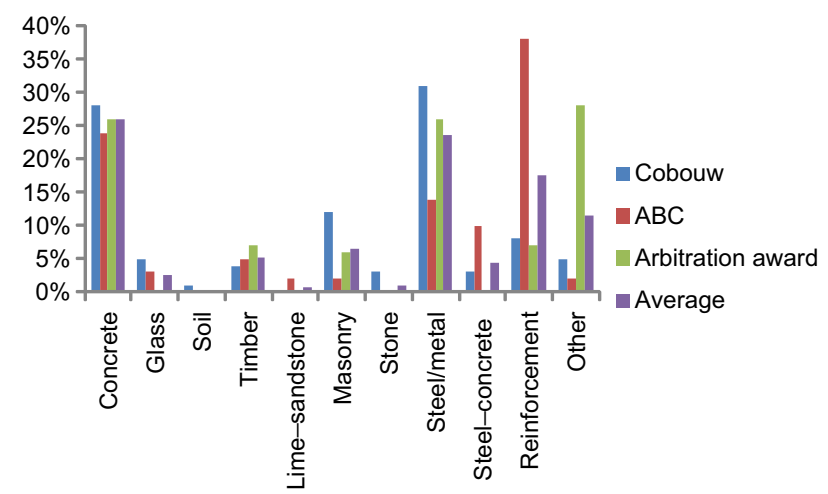

Figure 7. Materials involved

\subsubsection{Time of discovery}

Figure 9 shows that incidents from $\mathrm{ABC}$ registration are discovered in an earlier phase than cases in Cobouw and Dutch arbitration awards. This follows from the nature of each database; there is little or no sense in media attention or arbitration of errors detected in the design phase, because no damage has occurred yet. Results from Cobouw and arbitration awards show a noticeable resemblance to each other.

\subsection{Causes}

\subsubsection{Phase with main cause}

A remarkably large range of outcomes can be observed in Figure 10 between the three researches, especially for the design and use phase. Because many of the mistakes within $\mathrm{ABC}$ registration have already been discovered in the design phase, it is to be expected that the cause is more frequently found in the design phase. The average outcomes are within the

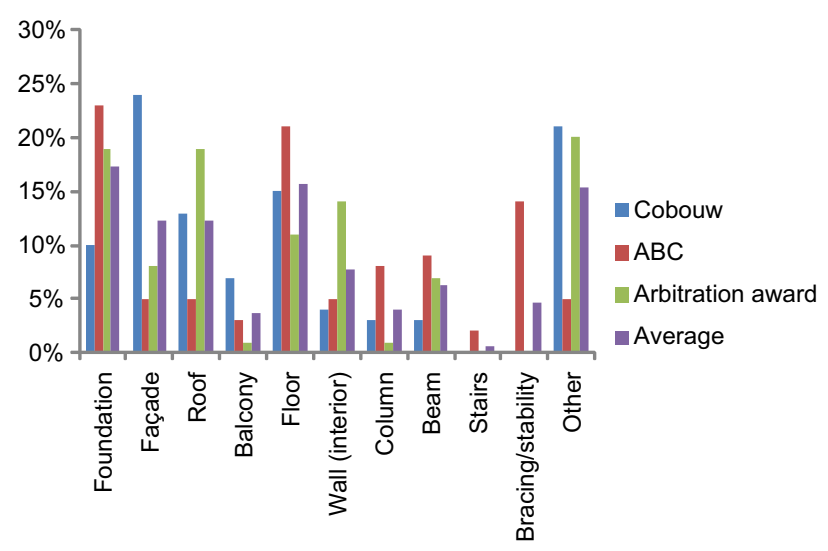

Figure 8. Construction elements 


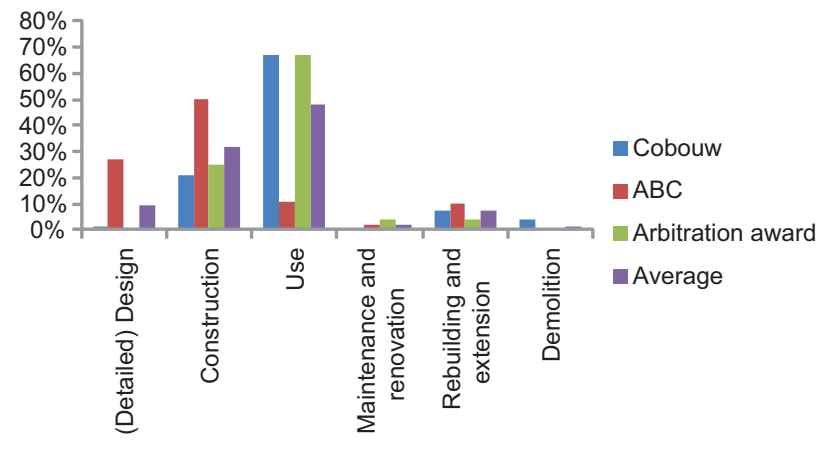

Figure 9. Time of discovery

range of international results, as presented by Fruehwald et al. (2007).

Furthermore, the databases show that the majority of failures are caused by a human error (see Table 2). A generic definition of human error is 'all those occasions in which a planned sequence of ... activities fails to achieve its intended outcome' (Reason, 1990). It is negatively related to the standard of good care - 'that level and quality of service ordinarily provided by other normally competent practitioners of good standing in that field, when providing similar services with reasonable diligence and best judgment in the same locality and the same time and under similar circumstances' (Ratay, 2012).

Design errors might range from conceptual, modelling, calculation and drawing errors to conflicts between calculation and drawing, or even the absence of a drawing or calculation. Construction errors might range from the choice of wrong materials or erroneous assemblage of elements to the application of an insufficient amount of material or erroneous sizing. Use

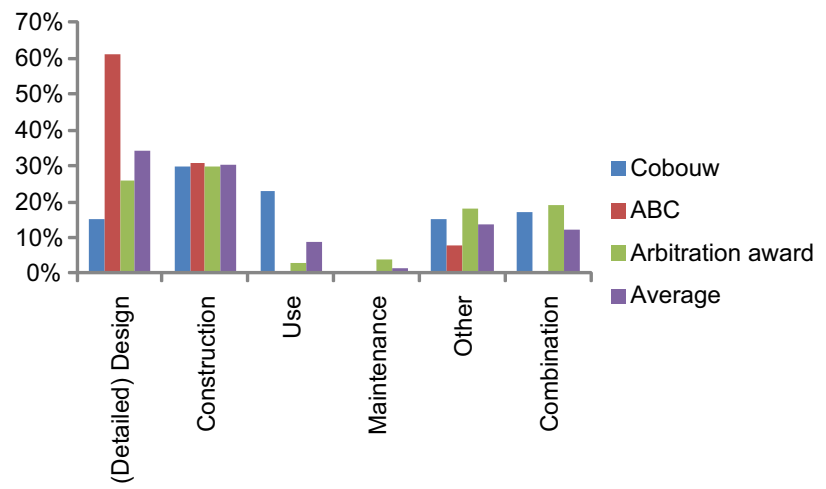

Figure 10. Phase with main causes errors usually have to do with overloading or sometimes with lack of inspection and maintenance.

Only a small part of the failures can be attributed to force majeure. For example, in Cobouw there are some cases where inadequate stainless steel was prescribed within swimming pools, in a period when the inadequacy of this type of material was not commonly known within practice. Another example is the situation where the actual loads (due, for instance, to rain, snow, traffic, impact) are higher than reasonably could have been expected. According to Ratay's definition it is hard to classify these situations as errors, which is the reason for classifying these as force majeure.

\subsubsection{Other contributing factors}

All three studies mention underlying factors, similar to the factors already mentioned in the cases of Maastricht and Twente. Examples are the complexity of the design, number of building participants in a project, presence of warnings, role of changes, time pressure, lack of budget, underdeveloped safety culture, unclear responsibilities, insufficient communication, lack of coordination and control, inadequate codes, the quality of the engineers and workmen, and working conditions. However, comparison of these factors is difficult, because the research studies did not focus on the same aspects, and often insufficient information on these aspects was available. In addition, one should be careful to attribute any safety effects to certain factors derived from failure cases, because it is usually not known to what extent these factors are also present in successful projects.

Nevertheless, the authors would like to highlight some significant outcomes. First, from the Cobouw research it was concluded that only about $15 \%$ of the cases could be classified as an unusual design. From this it can be concluded that complexity of design is not an essential requirement for failure. Second, from Cobouw and arbitration award research it appeared that in various cases changes were made in the design or construction phase. Without these changes, the failure would not have manifested itself. For $19 \%$ of the arbitration awards changes influenced the initiation of the failure. Third, from Cobouw and arbitration award research it is known that in many cases prior warnings were given by persons, after control or inspection, or by the structure itself, through the appearance of cracks or exceptional deformations. In the Cobouw database at least 168 cases were found where physical signs could be observed before damage or failure occurred to the full extent. However, it is not always certain if cracks and deformations are actually warnings before structural damage occurs to the full extent; in many situations it is just normal structural behaviour. Therefore, appropriate knowledge of physical signs that should be 
classified as warnings and the adequate response to them needs more attention.

\subsection{Consequences: fatalities}

Only Cobouw database provides sufficient data to analyse the number of fatalities due to structural failures. For the period of 17 years in total 43 fatalities were counted. Thirty-eight of them occurred during (re)construction phase and only five after completion of a building project. Arbitration awards only mention one fatality in their collection of cases; $\mathrm{ABC}$ registration does not list any fatalities.

These figures can be compared with those from the so-called 'Storybuilder' database. This database was set up by an international consortium (Ale et al., 2008) and uses reports of the Dutch Labour Inspectorate on job-related incidents within various sectors. This publicly available database is based on the safety concept of bow-ties, with on the left-hand side of the undesired event the actions and failed barriers leading to the incident and on the right-hand side the consequences of the undesired event. Currently the database contains approximately 23000 Dutch cases for the period 1998-2009 (RIVM, 2013), from which approximately 5600 are related to the building industry. Incidents related to failures of temporary or permanent structures have been selected. Examples are falls due to failure of scaffolding and impact due to contact with falling objects like beams, slabs or walls that were not adequately connected or stabilised.

According to Storybuilder on average $5 \cdot 3$ fatalities occurred each year in the Netherlands due to structural failures during work (job-related incidents in all considered sectors). The building sector is responsible for 3.7 fatalities annually whereas in the other sectors only 1.6 fatalities are counted yearly that can be attributed to structural failures. When considering that in the building industry nearly 0.5 million people are working in the building industry, compared to 8.3 million in the other sectors, it can be concluded that the building sector is a dangerous place to work, with respect to structural failures.

Cobouw mentions a smaller number of fatalities during construction, although it is the same order of magnitude (38 fatalities in 17 years $=2 \cdot 2$ per year, compared to 3.7 per year in Storybuilder). On the other hand, Cobouw records fatalities during work in other sectors very seldom $(2 / 17=0 \cdot 12$ per year, compared to 1.6 per year according to Storybuilder).

Fatalities due to structural failure for residential end-users are fortunately low. Cobouw mentions only three fatalities among residential end-users in 17 years, which is $0 \cdot 18$ fatalities per year. Table 3 depicts the probability of dying per year due to structural failure.

The exact numbers are rather sensitive to selection of cases in Storybuilder and should be considered with care. Furthermore, there might be some other deviations in these figures. Centraal Bureau voor de Statistiek (CBS) for instance mentions approximately 25 fatalities per year in the period 1998-2009 in the building sector, whereas Storybuilder only records approximately 18 fatalities per year in the same period. It seems that not every incident is reported to the Labour Inspection and/or included in the Storybuilder database. From these 18 fatalities only 3.7 are attributed to structural failures. Other job-related accidents are related to falling of persons (without structural inadequacies) and accidents due to explosions, fire, chemical exposure, car collisions and so on.

Although there might be some deviations from the actual figures, Table 3 gives a clear insight into the order of magnitude for the yearly probability of dying due to structural failures. For workers in the building sector this is $10^{-5}-10^{-6}$, for workers in other sectors this is $10^{-6}-10^{-7}$ and for citizens this is $10^{-7}-10^{-8}$.

In particular, the risk for residential end-users introduced by structures is low, compared to the (questionable) acceptable limit

\begin{tabular}{|c|c|c|c|c|}
\hline & $\begin{array}{l}\text { Population (average for period } \\
\text { 1998-2009 (CBS, 2013)) }\end{array}$ & $\begin{array}{l}\text { Storybuilder: } \\
\text { no. per year }\end{array}$ & $\begin{array}{l}\text { Cobouw: no. } \\
\text { per year }\end{array}$ & $\begin{array}{l}\text { Probability of dying: } \\
\text { no. per year }\end{array}$ \\
\hline $\begin{array}{l}\text { Workers in } \\
\text { building sector }\end{array}$ & 493000 & $3 \cdot 7$ & $2 \cdot 2$ & $3 \cdot 7 / 493000=7.5 \times 10^{-6}$ \\
\hline $\begin{array}{l}\text { Workers in other } \\
\text { sectors }\end{array}$ & $8 \cdot 3$ million & $1 \cdot 6$ & $0 \cdot 12$ & $1 \cdot 6 / 8 \cdot 3$ million $=1.9 \times 10^{-7}$ \\
\hline Residential & $16 \cdot 1$ million & - & $0 \cdot 18$ & $0 \cdot 18 / 16 \cdot 1$ million $=1 \cdot 1 \times 10^{-8}$ \\
\hline
\end{tabular}

Table 3. Probability of dying due to structural failures for various populations 
of $10^{-5}$ per year. This acceptable limit for residential end-users is a basis for calculation according to the Eurocode approach for existing buildings in the Netherlands (Vrouwenvelder and Scholten, 2008)

These conclusions should be drawn with care, because a catastrophe with a low probability of occurrence and high consequences could greatly influence the outcomes, but this kind of catastrophe did not occur in the observed period. Nevertheless, the conclusion is in line with, for instance, the Ciria research as cited by Madsen et al. (2006: p. 7) which concludes that the risk of death per $10^{4}$ exposed persons per year due to structural failures is 0.001 , which is equivalent to an individual risk of $10^{-7}$ per year.

\section{Conclusion}

The various types of data sources for failure databases and the analysis of this data differ in reliability. Therefore, it can be concluded that the outcomes of $\mathrm{ABC}$ registration and Dutch arbitration awards are considered more reliable than the outcomes of newspaper articles. However, because newspapers provide a significantly larger number of cases, they can be complementary and can give a valuable insight in trends.

Despite the reliability issues and differences in definitions and presentation of data, the results show resemblances and therefore some general conclusions can be drawn. First, data from databases reveal that the annual number of fatalities among residents due to structural failures stays within limits of the safety philosophy behind the Eurocode. However, the building sector is more dangerous to work in than most of the other sectors, with respect to structural failures.

Furthermore, the three databases reveal many characteristics of failures and give information on causes. Buildings are involved in approximately $85 \%$ of all reported incidents. Horizontal construction elements are more vulnerable to failures than vertical ones. Steel structures tend to be more prone to errors than concrete structures, although this statement should be supported by additional research. It appears that the cause of structural failure is approximately $35 \%$ in the design phase, approximately $30 \%$ in the construction phase and less often in the use and maintenance phase (approximately 10\%). A reasonable number of cases (over 10\%) have a combination of design and construction errors. Because this research showed that failures are almost equally caused in both design and construction phases, engineers cannot pretend that most errors are made in the execution phase and contractors cannot claim that the majority of failures originate in the design phase.

Finally, the databases present some remarkable outcomes of process factors probably related to the occurrence of failures. These factors include the influence of changes in design or construction and presence of warnings given by people or by the structure itself. This indicates an opportunity to reduce failure probability by better procedures dealing with changes and warning indications.

It has been shown that combining results of various sources of structural failures gives a more balanced view of the characteristics of structural incidents than using a single source. This comparison study has provided an insight into the causes of failures and can be used as a starting point for international comparison. A European multidisciplinary database project on structural failures based on a firm theoretical background might be a relevant initiative.

\section{Discussion of the current Eurocode approach}

This research might fuel a discussion of the current two-way Eurocode approach. The first way is the approach with structural calculations based on a probabilistic philosophy. The second way is the quality assurance approach, with for instance suggested control procedures, to deal with human errors. In this approach human errors are considered as accidental loads.

From this study it appeared that about $90 \%$ of the failures are caused by human errors, although human behaviour is not included in the probabilistic approach for calculations in the Eurocode. However, the yearly probability of dying as a resident due to structural failures stays within limits for the observed time interval, although no catastrophe with low probability-high consequences did occur in the observed period.

This seems to be a paradox, but can be explained.

Real structures are stronger than they appear on paper. It is supposed that structures behave more strongly than calculated owing to redistribution of forces and better material properties than taken into account in calculations. For concrete structures the strength usually increases during a structure's lifetime.

- Warning behaviour limits consequences. An example of this phenomenon is the case of the Bos and Lommer plaza in the Netherlands (Priemus and Ale, 2010). After some major cracks in the concrete deck, the adjacent shops, houses and offices were evacuated. Investigations uncovered serious flaws in the structure of the deck and of the adjacent multi-purpose building. Adequate structural measures were taken, thus limiting the consequences to financial damage only.

Because human factors are the most important causes of failure, it seems to be relevant to include these in the probabilistic 
Eurocode approach. A method with this purpose has been proposed (De Haan et al., 2013), but deriving reliable failure probabilities for both design and construction phases is a very difficult challenge.

With current knowledge this integration of a quantification of human errors with Eurocode's probabilistic structural calculations does not lead to satisfying results. Research effort in this field is necessary.

In the current two-way Eurocode approach the structural calculations based on probabilistic principles generally lead to safe, but usually conservative structures, by underestimating the influence of overcapacity and warning behaviour. However, the quality assurance approach too often seems to be faulty. The majority of failures can be attributed to human errors, influenced by organisational factors. Quality assurance in the Eurocode and, moreover, in building projects needs more attention to actually reduce the probability of fatal incidents.

Over recent years a lot of attention has been paid to robustness of the product, where robustness can be defined as the insensitivity of a structure to local failure (Starossek, 2006). This research shows that future efforts have to focus on the robustness of the process too.

\section{Acknowledgements}

The authors would like to thank Martijn Mud (RPS) for his assistance in abstracting relevant information from the Storybuilder database, Hayo Hendrikse (DUT) for assistance in the set-up of the Cobouw database and Professor Jonathan Wood for providing guidance in earlier versions of this paper.

\section{REFERENCES}

Ale BJM, Baksteen H, Bellamy LJ et al. (2008) Quantifying occupational risk: the development of an occupational risk model. Safety Science 46(2): 176-185.

Boot WF (2011) Constructieve schade - een analyse van oorzaken aan de hand van jurisprudentie. Tijdschrift voor Bouwrecht 6: 41-49, (in Dutch).

Breysse D (2012) Forensic engineering and collapse databases. Proceedings of the Institution of Civil Engineers - Forensic Engineering 165(2): 63-75.

CBS (2013) Http://www.cbs.nl (accessed 30/05/2013).

CUR (2010) Falende Constructies: Case-onderzoek naar Structurele Oorzaken van Falen en Maatregelen die dat Tegengaan. CURnet, Gouda, the Netherlands, CUR 232, (in Dutch).

De Haan J, Terwel KC and Al-Jibouri SHS (2013) Design of a human reliability assessment model for structural engineering. Proceedings of 22nd ESREL 2013 Conference, Amsterdam, the Netherlands in press.
Dieteren GGA and Waarts PH (2009) Samenvatting Analyse van Schades. TNO Bouw en Ondergrond, Delft, the Netherlands, (in Dutch).

Dutch Safety Board (2012) Instorten van het dak van de aanbouw van het stadion van FC Twente, te Enschede. Dutch Safety Board, The Hague, the Netherlands (in Dutch).

EIB (2012) Verwachtingen Bouwproductie en Werkgelegenheid 2012. Economisch Instituut voor de Bouw, Amsterdam, the Netherlands, (in Dutch).

Fruehwald E, Serrano E, Toratti T et al. (2007) Design of Safe Timber Structures- How Can We Learn from Structural Failures in Concrete, Steel and Timber? Lund Institute of Technology, Lund, Sweden.

Loss J (1987) Aepic project: update. Journal of Performance of Constructed Facilities 1(1): 11-29.

Madsen HO, Krenk S and Lind NC (2006) Methods of Structural Safety. Dover Publications, Mineola, IA, USA.

Nelisse RML and Terwel KC (2011) Constructieve Veiligheid Evaluatie ABCmeldpunt: Structurele Verbetering? CURnet, Gouda, the Netherlands, CUR 235, (in Dutch).

Priemus $\mathrm{H}$ and Ale B (2010) Construction safety, an analysis of systems failure. The case of the multifunctional Bos\&Lommerplein estate, Amsterdam. Safety Science 48(2): 111-122.

Ratay R (2012) Education to prepare for the practice of forensic engineering. Proceedings of the Institution of Civil Engineers - Forensic Engineering 165(3): 111-113.

Reason J (1990) Human Error. Cambridge University Press, New York, USA.

RIVM (Rijksinstituut voor Volksgezondheid en Milieu) (2013) Storybuilder. RIVM, the Netherlands, see http://www.rivm. nl/Onderwerpen/Onderwerpen/S/Storybuilder (accessed 30/05/2013).

Schneider J and Matousek M (1976) Untersuchungen zur Struktur des Sicherheitsproblems bei Bauwerken. Institut fuer Baustatik und Konstruktion, ETHZ, Zurich, Switzerland.

Starossek U (2006) Progressive collapse of structures: nomenclature and procedures. Structural Engineering International 16(2): 113-117.

Terwel KC (2012) Uitgebreide Samenvatting Uitkomsten Database Constructieve Incidenten Cobouw 171212. Delft University of Technology, Delft, the Netherlands, (in Dutch).

Terwel KC, Nelisse RML and Mans DG (2012) Confidential reporting of mistakes in structural design and execution. In Proceedings of IABSE Conference Global Thinking in Structural Engineering: Recent Achievements. Sharm el Sheikh, Egypt (Saad F (ed.)). IABSE, Zurich, Switzerland.

Terwel KC, Boot WF and Nelisse RML (2013) Structural incidents in the Netherlands: a comparison of three databases. In Proceedings of the 5th International Conference on Forensic 
Engineering 2013: Informing the Future with Lessons from the Past (Georgopoulos C (ed.)). Institution of Civil Engineers, London, UK.

USP Marketing Consultancy (2008) Faalkosten in de Bouw naar Hoogtepunt. USP Marketing Consultancy, Rotterdam, the Netherlands, (in Dutch).
Van Herwijnen F (2009) Leren van Instortingen. Bouwen met staal, Zoetermeer, the Netherlands, (in Dutch).

Vrouwenvelder ACWM and Scholten NPM (2008)

Veiligheidsbeoordeling Bestaande Bouw.

Achtergrondrapport Bij NEN8700. NEN/TNO Bouw, Delft, the Netherlands, (in Dutch).

\section{WHAT DO YOU THINK?}

To discuss this paper, please email up to 500 words to the editor at journals@ice.org.uk. Your contribution will be forwarded to the author(s) for a reply and, if considered appropriate by the editorial panel, will be published as discussion in a future issue of the journal.

Proceedings journals rely entirely on contributions sent in by civil engineering professionals, academics and students. Papers should be 2000-5000 words long (briefing papers should be 1000-2000 words long), with adequate illustrations and references. You can submit your paper online via www.icevirtuallibrary.com/content/journals, where you will also find detailed author guidelines. 